\section{Modern ultrasound imaging of pancreatic tumors}

\author{
Christoph F. Dietrich ${ }^{1,2}$, Christian Jenssen ${ }^{3}$ \\ ${ }^{1}$ Medical Department, Caritas-Krankenhaus, Bad Mergentheim, Germany; ${ }^{2}$ Sino-German \\ Research Center of Ultrasound in Medicine, The First Affiliated Hospital of Zhengzhou \\ University, Zhengzhou, China; ${ }^{3}$ Department of Internal Medicine, Krankenhaus Märkisch \\ Oderland, Strausberg/Wriezen and Brandenburg Institute for Clinical Ultrasound, Neuruppin, \\ Germany
}

In patients with solid pancreatic lesions (SPLS), the differential diagnosis must be evaluated to determine whether radical surgery, pancreatic parenchyma-saving strategies, or follow-up is indicated. Contrast-enhanced (endoscopic) ultrasonography and elastography facilitate the further characterization of SPLS. The majority of cases of pancreatic ductal adenocarcinoma exhibit hypoenhancement with contrast-enhanced ultrasonography. Elastographically soft SPLS are benign with very few exceptions, whereas stiffer SPLs can be malignant or benign. This article reviews the current use of modern ultrasound imaging techniques, including contrast-enhanced ultrasonography and elastography, for the detection and characterization of SPLs. In particular, the unexcelled diagnostic potential of multiparametric endoscopic ultrasonography to detect and characterize small SPLs is highlighted.

Keywords: Ultrasound; Real-time endosonography; Tissue elastography; Pancreas;

Neuroendocrine tumors

\section{Introduction: the Smaller the Lesion, the Better the Prognosis}

Symptomatic pancreatic ductal adenocarcinoma (PDAC), which is the most commonly diagnosed solid malignant tumor of the pancreas, is generally diagnosed at a late stage with or without metastases $[1,2]$. Most internationally recognized guidelines [3-6] recommend radical surgery for all small solid pancreatic lesions (SPLS) unless a strong suspicion of an etiology other than PDAC is suspected or contraindications are present. In earlier times, the preoperative diagnosis of PDAC $<20 \mathrm{~mm}$ (T1) was reported to be $<5 \%$; in a large series including 13,131 patients, only $3.1 \%$ of cases were staged as stage T1a [1]. Very early diagnosis of this tumor in asymptomatic stages is crucial for improving its prognosis [7-11]. Data from the Surveillance, Etiology and End Results (SEER) program [12] as well as from the Japanese Pancreatic Cancer Registry [13] show that the smaller the lesion at time of diagnosis, the longer the expected 5-year survival rate. In the SEER database (2000-2010), PDAC $\leq 20 \mathrm{~mm}$ account for only $14.8 \%$ of patients with pancreatic cancer, but for $28.2 \%$ of 5 -year survivors [12]. The 5 -year survival rate may be as high as $30 \%-60 \%$ in very small PDAC with curative radical surgery $[9,14-17]$, compared to a rate of $<5 \%$ in general (https://seer.cancer.gov/). Progress

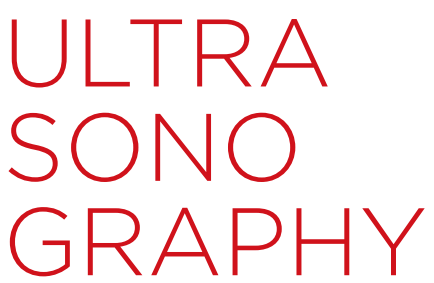

\section{REVIEW ARTICLE}

https://doi.org/10.14366/usg. 19039 pISSN: 2288-5919 • elSSN: 2288-5943 Ultrasonography 2020;39:105-113

Received: July 6, 2019

Revised: August 25, 2019

Accepted: August 27, 2019

Correspondence to: Christoph F. Dietrich, MD, PhD, MBA, Medical Department, CaritasKrankenhaus, Uhlandstr. 7, D-97980 Bad Mergentheim, Germany

Tel. +49-(0)7931-58-2201

Fax. +49-(0)7931-58-2290

E-mail: Christoph.dietrich@ckbm.de
This is an Open Access article distributed under the terms of the Creative Commons Attribution NonCommercial License (http://creativecommons.org/ licenses/by-nc/4.0/) which permits unrestricted noncommercial use, distribution, and reproduction in any medium, provided the original work is properly cited.

Copyright (C) 2020 Korean Society of Ultrasound in Medicine (KSUM)

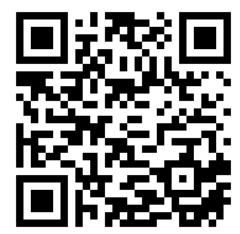

How to cite this article: Dietrich CF, Jenssen C. Modern ultrasound imaging of pancreatic tumors. Ultrasonography. 2020 Apr;39(2):105-113. 
from early PDAC to stage T4 may occur in less than 1 year [1]. In today's view, an SPL diameter of $\geq 15-20 \mathrm{~mm}$ is approximately $80 \%$ predictive of PDAC $[7,18,19]$. Neuroendocrine neoplasia has a much better 5 -year survival, depending on the specific histology and hormone production $[20,21]$.

The accuracy of traditional imaging methods, including ultrasonography (US), computed tomography (CT), and magnetic resonance imaging (MRI), in the differential diagnosis of pancreatic masses was found to be disappointing $[6,16,22]$. CT was the recommended technique for diagnosis and staging of pancreatic cancer $[14,16,22-24]$, but showed unsatisfying results for the detection of small SPLs $(<20 \mathrm{~mm})[7,25,26]$. CT does not reliably allow the differential diagnosis of small SPLs $[9,27]$. Endoscopic ultrasonography (EUS) is considered to be the imaging method of choice to exclude PDAC $[24,28,29]$. Based on 22 studies including 1,170 cases, the pooled sensitivity of EUS for the detection of SPLS was $94 \%$, which is markedly higher than the reported results for multidetector CT, MRI, and transabdominal US [30]. According to meta-analysis data, EUS has a diagnostic yield of $70 \%$ for detecting SPLs in patients with indeterminate results from multidetector CT scans, in $42 \%$ of whom the final diagnosis was PDAC [31]. Moreover, EUS offers the opportunity to detect asymptomatic PDAC [32]. A recent retrospective multicenter analysis of 200 small PDACs showed that in only $52.6 \%$ of cases the tumor diagnosis was possible due to direct visualization of the tumor by imaging techniques. In $74.8 \%$ of the cases, dilatation of the main pancreatic duct (MPD) was the clue for the diagnosis. The sensitivity of EUS for tumor detection was $92.4 \%$, whereas transcutaneous ultrasonography (TUS), CT, and MRI had a sensitivity of only $67.3 \%$, $65.8 \%$, and $57.5 \%$, respectively [33]. Other studies using TUS and EUS have highlighted the high diagnostic value of these techniques for the detection of MPD dilatation or stricture in order to diagnose small PDACs [34-36]. The unmatched diagnostic ability of EUS was also described for the detection of pancreatic neuroendocrine tumors (PNETs). A retrospective study showed that CT overlooked $68 \%$ of PNETs measuring $<10 \mathrm{~mm}$, whereas the sensitivity of EUS was $100 \%$ [37]. According to a recent meta-analysis, EUS has an additional diagnostic yield of $28 \%$ over radiological imaging and up-to-date scintigraphic techniques to detect PNETs [38]. Several studies have shown EUS to be superior for the characterization of SPLS $[25,39-43]$. EUS is recommended by the National Comprehensive Cancer Network guidelines [14]. Contrast-enhanced imaging techniques allow improved characterization before radical surgery and fine-needle biopsy successfully enables the preoperative differential diagnosis in many circumstances $[2,7]$. EUS-guided tissue sampling is $85 \%-92 \%$ sensitive and nearly $100 \%$ specific for the diagnosis of pancreatic malignancy [44-47]. However, a recent study showed that the sensitivity of EUS-guided fine-needle aspiration significantly decreased with decreasing mass size [48]. In conclusion, for the detection and characterization of small SPLs, EUS is the imaging technique of choice.

\section{Contrast-Enhanced Ultrasonography and/or Contrast-Enhanced Endoscopic Ultrasonography}

The introduction of contrast-enhanced EUS (CE-EUS) has improved the performance of endoscopic imaging $[49,50]$. A multicenter pancreatic US study (PAMUS) with more than 1,000 patients and other studies using contrast-enhanced ultrasonography (CEUS) and CE-EUS showed an improved diagnostic accuracy for the characterization of focal pancreatic lesions [29,51-53]. Metaanalyses demonstrated a $90 \%$ accuracy of CEUS and CE-EUS for differentiating PDAC from other etiologies of SPLs [54-57]. Recent data from 394 asymptomatic patients or patients with unspecific symptoms, with incidentally found small solid SPLs $\leq 15 \mathrm{~mm}$ and a definite histological or cytological diagnosis, were retrospectively evaluated. Patients with significant weight loss, jaundice, or a history of chronic pancreatitis were excluded [32]. Furthermore, patients with defined hormone production, genetically determined diseases, and cystic or semisolid lesions were excluded from those guidelines $[21,58,59]$. Patients with neuroendocrine neoplasia and hormone production were analyzed as well and the results were published in a separate paper [21]. The first imaging methods used for detection according to a prior consensus were TUS, EUS, CT, and $\mathrm{MRI}$, with varying work-ups depending on the availability of imaging techniques, biopsy, and surgery. Only 146 of 394 small SPLs (37\%) were finally diagnosed as PDAC. In the subgroup of SPLs measuring exactly $15 \mathrm{~mm}(\mathrm{n}=83), 51$ lesions proved to be PDAC (62\%). In contrast, only 95 of $311 \mathrm{SPLs}<15 \mathrm{~mm}(31 \%)$ were diagnosed as PDAC $(P<0.01)$ [32]. The most important differential diagnosis of PDAC is PNET. In fact, 156 of the 394 small SPLs (40\%) turned out to be typically hyperenhancing $[51,52]$ PNETs, of which 129 PNETs (83\%) were benign and $27(17 \%)$ malignant [32]. The third most common etiology was pancreatic metastases ( $n=28,7 \%$ ). Other differential diagnoses included often hypervascular serous microcystic cystadenoma, solid pseudopapillary tumor, non-Hodgkin lymphoma, focal pancreatitis, intrapancreatic accessory spleen, and hamartoma $[28,29,51,52]$, whereas mucin-filled intraductal papillary mucinous neoplasia and isolated necrosis are non-enhancing [32]. It can be concluded that the smaller an SPL, the less likely the diagnosis of PDAC and the more frequent the diagnosis of PNET and other rare etiologies.

CEUS and/or CE-EUS was performed in 219 of 394 patients using 
an intravenous injection of $2.4 \mathrm{~mL}$ (CEUS) or $4.8 \mathrm{~mL}$ (CE-EUS) of SonoVue according to the guidelines of the European Federation of Societies for Ultrasound in Medicine and Biology (EFSUMB) [28,6063]. Isoenhancement, hyperenhancement, or hypoenhancement in comparison to the surrounding pancreatic parenchyma was documented [32,64]. In 57 of 62 patients (92\%), PDAC exhibited hypoenhancement, whereas in non-PDAC patients 132 of 157 SPLS (84\%) showed isoenhancement or hyperenhancement in comparison to the surrounding pancreatic parenchyma. In addition, 91 of 102 PNETs (89\%) were hyperenhancing or isoenhancing, resulting in a correct differential diagnosis of PDAC and non-PDAC in 189 of 219 patients (86\%) [32]. The results using CEUS were better compared to $\mathrm{CT}$; $\mathrm{CT}$ did not delineate a focal pancreatic lesion in 14 of the 38 patients with complete reports of CE-EUS and CT (37\%; PDAC, $n=6$ and PNET, $n=8$; median diameter $8 \mathrm{~mm}$ [range, 4 to $12 \mathrm{~mm}$ ]) [32] and the ultrasound contrast agent SonoVue was

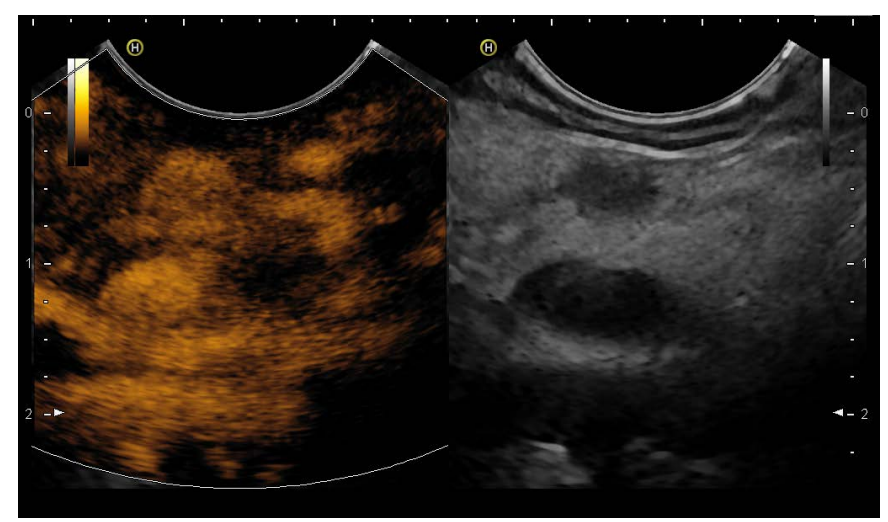

A

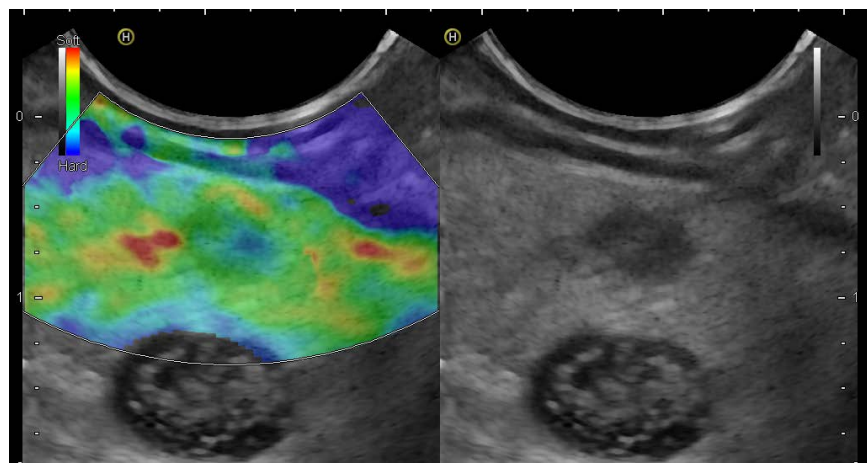

C

Fig. 1. Neuroendocrine neoplasia.

A, B. Focal pancreatic lesions that were hyperenhancing on contrast-enhanced imaging techniques $(7 \times 6 \mathrm{~mm}$, between markers) using endoscopic ultrasonography (A) and transcutaneous contrast-enhanced ultrasonography (B) are shown. C. The soft elastographic image is shown as well, indicating a benign lesion. D. The handheld device Vscan also demonstrates the lesion. A neuroendocrine neoplasia was diagnosed by biopsy and histopathological evaluation. highly sensitive due to being strictly intravascular [65]. These results are in concordance with the findings published for more than 1,000 histologically proven focal pancreatic lesions and in earlier studies using CEUS techniques $[29,49]$. Eye-catching features have been published for the imaging of serous microcystic neoplasia with only microscopically detectable cysts mimicking a solid lesion [66].

In conclusion, and in accordance with the published literature, CEUS and CE-EUS allow the differential diagnosis of solid pancreatic tumors in about $90 \%$ of cases. This knowledge has been reflected in recent guidelines $[60,61]$ and should be applied for costeffectiveness reasons as well [67].

\section{EUS versus TUS}

In addition to the recently published results for small SPLs using conventional US, TUS, and EUS [32], we herein report data on

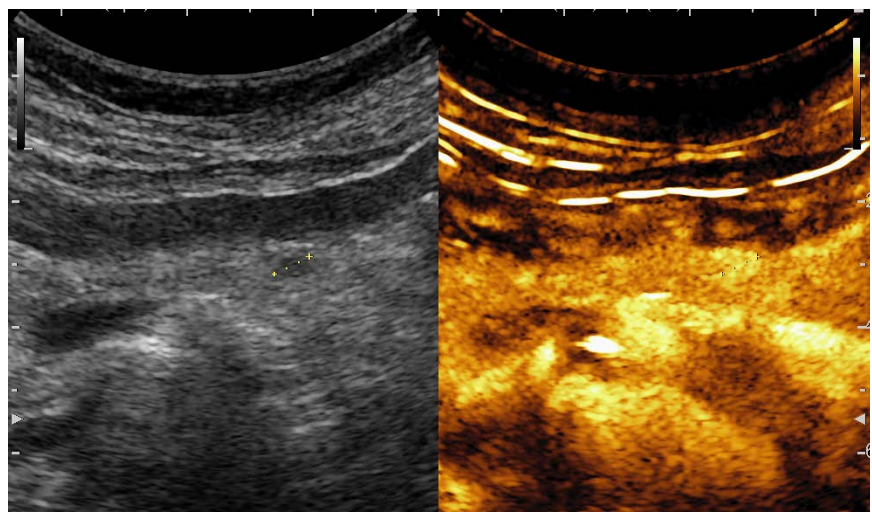

B

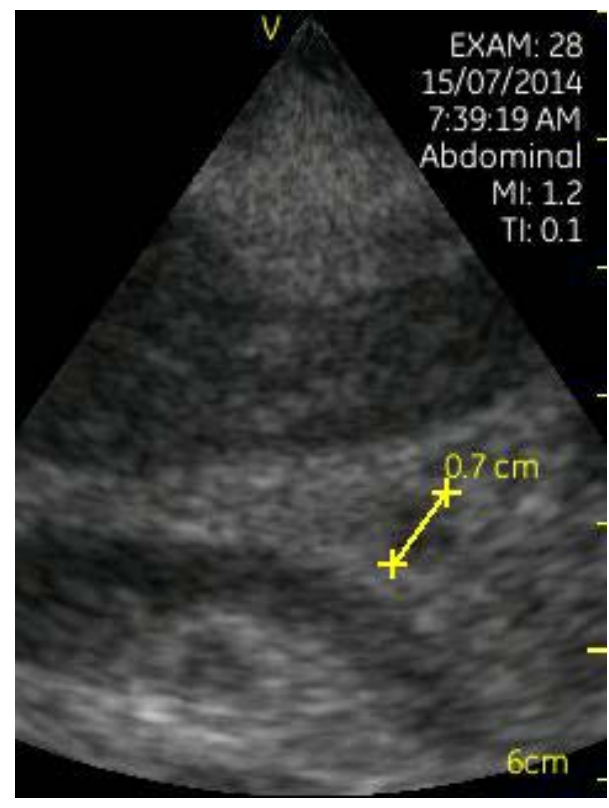


the comparative results obtained using TUS and EUS. TUS was performed prior to EUS in 45 patients (median age: 59 years; range, 18 to 81 years; 20 males and 25 females) with 25 (56\%) malignant and $20(44 \%)$ benign SPLs. In 5 of 45 patients (11\%), the SPL was not detected by TUS prior and after EUS. In six of 45 patients (13\%), detection of the lesion on TUS and CEUS were only possible with knowledge of the EUS findings. In 34 of 45 patients (76\%), the SPL was detected by TUS prior to the EUS examination and CEUS was performed as described. The CEUS results were concordant except in one patient with a hyperenhancing lesion using EUS that was shown as hypoenhancing by TUS. We conclude that most SPLS can be detected by TUS, and CEUS evaluation is possible for further characterization (Figs. 1, 2) [63]. The value of handheld point-of-care devices remains to be determined [68-72].

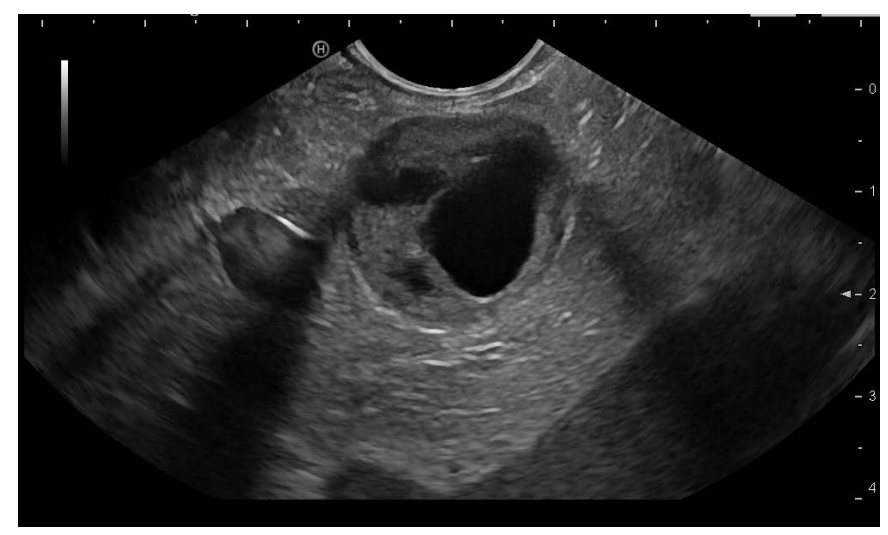

A

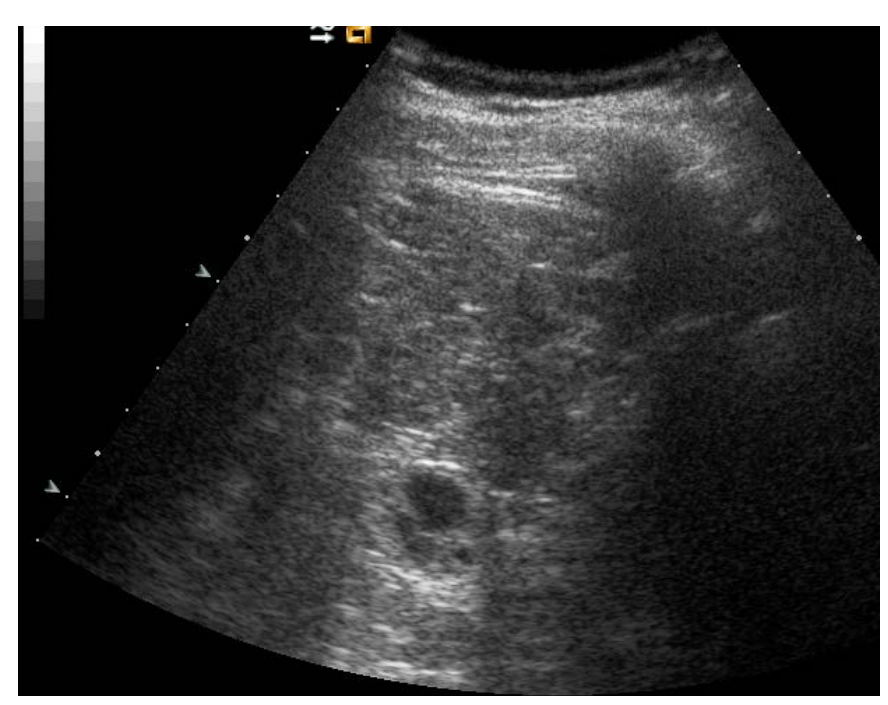

C

\section{Ultrasound Elastography}

Ultrasound elastography (USE) allows the assessment of tissue stiffness by virtual palpation. Two main types of USE are used for the evaluation of the pancreas and of other organs [73-83]. Ultrasoundbased strain elastography using EUS has been established for the assessment of small focal pancreatic lesions and the examination technique has been described in detail, including the appropriate transducer, frequency selection, frame rate, line density, palpation speed and amplitude, noise filters, persistence, dynamic range of elasticity, and other quality parameters (e.g., strain graph display) $[80,81,83-86]$. Soft small SPLs are typically benign, whereas stiffer (harder) SPLs in otherwise healthy pancreatic parenchyma can be malignant or benign. Recently a study was performed of 218

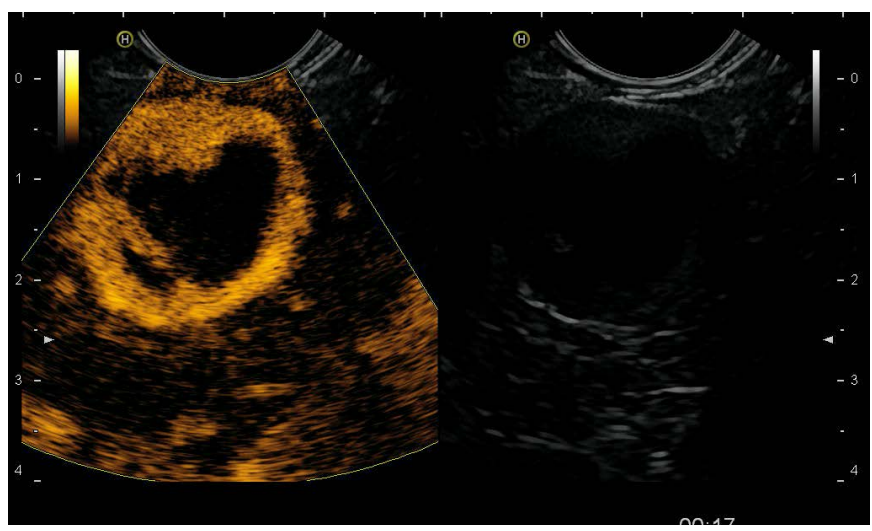

B

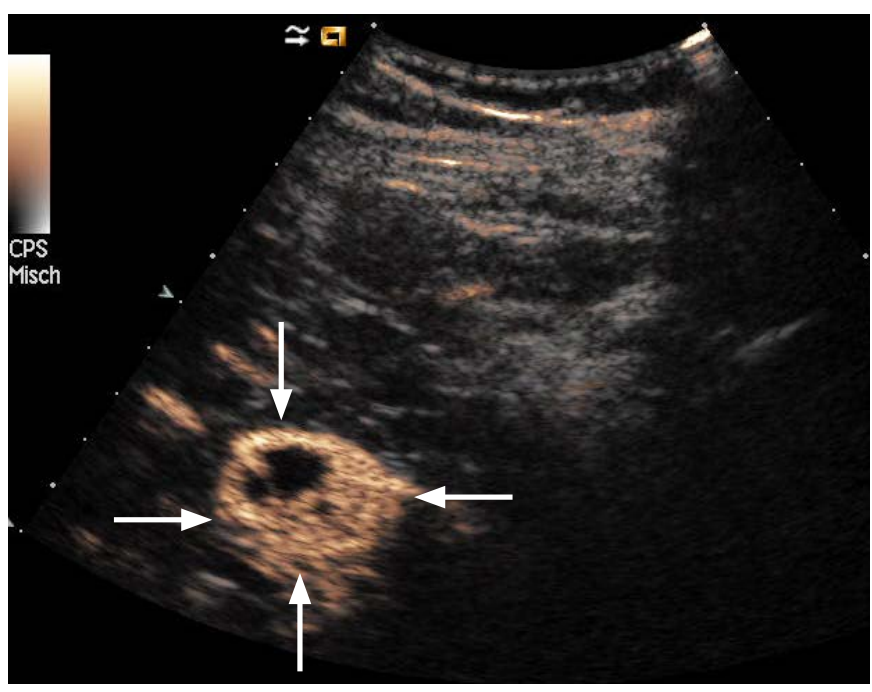

D

Fig. 2. Neuroendocrine mixed solid-cystic neoplasia.

Solid-cystic focal pancreatic lesions (marked with arrows) using B-mode (A) that were hyperenhancing on contrast-enhanced endoscopic ultrasonography (B) and transcutaneous B-mode (C) and contrast-enhanced ultrasonography (D) are shown. A neuroendocrine neoplasia was diagnosed by biopsy and histopathological evaluation. 
patients with SPLs $\leq 15 \mathrm{~mm}$ and a definite histological diagnosis [87]. In this particular group of small SPLs, $50 \%$ turned out to be soft compared to the surrounding pancreatic parenchyma. It could be shown that especially in patients with small pancreatic lesions, EUS elastography can rule out malignancy with a high level of certainty if the lesion is displayed as soft. In larger SPLs (>30 mm) the results are less convincing mainly due to the heterogenicity of the lesions but also because of concomitant changes of the surrounding pancreatic parenchyma [87]. The examination technique must follow certain rules, which have been described in detail $[85,86]$. Elastography is not able to decisively differentiate focal pancreatitis from PDAC, since chronic focal pancreatitis can also be stiffer than the otherwise healthy pancreatic parenchyma. Strain elastography is also useful in diagnosing autoimmune pancreatitis since the entire organ shows stiffer tissue properties before B-mode changes are visible [88-92]. Circumscript pancreatic tuberculosis is also stiffer than the surrounding pancreatic parenchyma $[93,94]$, whereas the application and correct interpretation of elastography in chronic pancreatitis is more difficult and semiquantitative strain-exploiting elastographic techniques are preferred.

The current role of shear wave elastography remains to be determined. Shear wave measurements are higher in PDAC, with Shear wave velocities $>3 \mathrm{~m} / \mathrm{sec}$ [95-98], compared to the surrounding pancreatic parenchyma.

\section{Conclusion}

In patients with SPLs, etiological differentiation is necessary to facilitate reasonable decisions on further management: radical surgery in patients with resectable PDAC, oncological treatment in patients with non-resectable malignancy, pancreatic parenchymasaving strategies or surveillance in benign neuroendocrine neoplasia or follow-up in small benign lesions (Fig. 3) [32].

Based on the enhancement pattern in CEUS and elastography

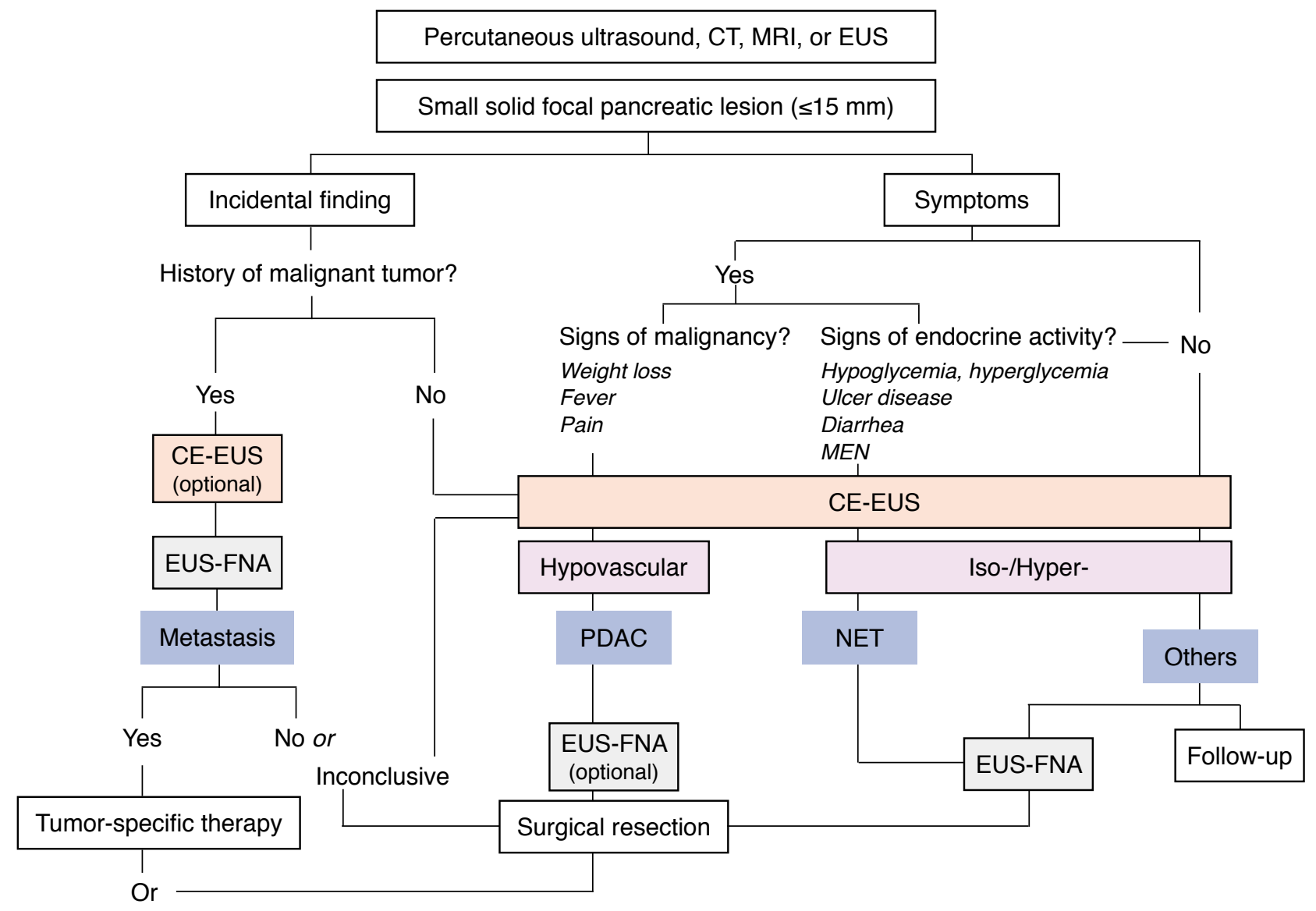

Fig. 3. Diagnostic algorithm. Diagnostic algorithm for small pancreatic lesions is shown. CT, computed tomography; MRI, magnetic resonance imaging; EUS, endoscopic ultrasonography; MEN, multiple endocrine neoplasia; CE-EUS, contrast-enhanced EUS; EUS-FNA, EUS with fine-needle aspiration; PDAC, pancreatic ductal adenocarcinoma; NET, neuroendocrine tumor. Adapted from Dietrich and Burmester, Endosc Ultrasound 2017;6:S106-S110 [50], according to the Creative Commons license [50]. 
findings, further characterization of SPLs is possible. Hypovascularity is observed in approximately $90 \%$ of PDACs. Soft SPLs are benign, with very few exceptions, whereas stiffer (harder) SPLs in otherwise healthy pancreatic parenchyma can be malignant or benign.

Approximately $60 \%$ of small SPLs $(\leq 15 \mathrm{~mm})$ are diagnosed with etiologies other than PDAC $[28,51,52]$. In patients with hypervascular and/or soft SPLs, tissue acquisition is therefore recommended prior to treatment decisions, as radical surgery might not be appropriate. Nevertheless, about $40 \%$ of patients with small SPLS revealed PDAC at a very early stage, with a better prognosis. Patients with a hypovascular SPL $\leq 15 \mathrm{~mm}$ should be primarily and radically operated since this finding is indicative of PDAC.

In patients with serous cystadenoma, mesenchymal lesions, intrapancreatic accessory spleen, and non-functional PNETs $<10 \mathrm{~mm}$ with a Ki67 index $<3 \%$, follow-up may be recommended, whereas PNETs $>10 \mathrm{~mm}$ with a Ki67 index $>3 \%$ will often be operated due to their malignant potential [99].

ORCID: Christoph F. Dietrich: https://orcid.org/0000-0001-6015-6347; Christian Jenssen: https://orcid.org/0000-0002-7008-6650

\section{Author Contributions}

Conceptualization: Dietrich CF, Jenssen C. Drafting of the manuscript: Dietrich CF, Jenssen C. Critical revision of the manuscript: Dietrich CF, Jenssen C. Approval of the final version of the manuscript: all authors.

\section{Conflict of Interest}

The authors thank the Bad Mergentheimer Leberzentrum e.V. for support.

\section{References}

1. Yu J, Blackford AL, Dal Molin M, Wolfgang CL, Goggins M. Time to progression of pancreatic ductal adenocarcinoma from low-to-high tumour stages. Gut 2015;64:1783-1789.

2. van Heerde MJ, Biermann K, Zondervan PE, Kazemier G, van Eijck $\mathrm{CH}$, Pek $\mathrm{C}$, et al. Prevalence of autoimmune pancreatitis and other benign disorders in pancreatoduodenectomy for presumed malignancy of the pancreatic head. Dig Dis Sci 2012;57:24582465.

3. Seufferlein T, Bachet JB, Van Cutsem E, Rougier P; ESMO Guidelines Working Group. Pancreatic adenocarcinoma: ESMO-ESDO Clinical Practice Guidelines for diagnosis, treatment and follow-up. Ann Oncol 2012;23 Suppl 7:vii33-vii40.

4. Seufferlein T, Porzner M, Becker T, Budach V, Ceyhan G, Esposito I, et al. S3-guideline exocrine pancreatic cancer. Z Gastroenterol
2013;51:1395-1440.

5. Tempero MA, Arnoletti JP, Behrman S, Ben-Josef E, Benson AB 3rd, Berlin JD, et al. Pancreatic adenocarcinoma. J Natl Compr Canc Netw 2010;8:972-1017.

6. Asbun HJ, Conlon K, Fernandez-Cruz L, Friess H, Shrikhande SV, Adham $M$, et al. When to perform a pancreatoduodenectomy in the absence of positive histology? A consensus statement by the International Study Group of Pancreatic Surgery. Surgery 2014; 155:887-892.

7. Wang W, Shpaner A, Krishna SG, Ross WA, Bhutani MS, Tamm EP, et al. Use of EUS-FNA in diagnosing pancreatic neoplasm without a definitive mass on CT. Gastrointest Endosc 2013;78:73-80.

8. Matsuoka L, Selby R, Genyk Y. The surgical management of pancreatic cancer. Gastroenterol Clin North Am 2012;41:211-221.

9. Aso $A$, Ihara $E$, Osoegawa $T$, Nakamura $K$, Itaba $S$, Igarashi $H$, et al. Key endoscopic ultrasound features of pancreatic ductal adenocarcinoma smaller than $20 \mathrm{~mm}$. Scand J Gastroenterol 2014;49:332-338.

10. Gleason MX, Mdzinarishvili T, Are C, Sasson A, Sherman A, Shats 0 , et al. Prognostic estimator of survival for patients with localized and extended pancreatic ductal adenocarcinoma. Cancer Inform 2013;12:103-114.

11. Chari ST. Detecting early pancreatic cancer: problems and prospects. Semin Oncol 2007;34:284-294.

12. Hur C, Tramontano AC, Dowling EC, Brooks GA, Jeon A, Brugge WR, et al. Early pancreatic ductal adenocarcinoma survival is dependent on size: positive implications for future targeted screening. Pancreas 2016;45:1062-1066.

13. Egawa S, Toma H, Ohigashi H, Okusaka T, Nakao A, Hatori T, et al. Japan Pancreatic Cancer Registry; 30th year anniversary: Japan Pancreas Society. Pancreas 2012;41:985-992.

14. Scialpi M, Cagini L, Pierotti L, De Santis F, Pusiol T, Piscioli I, et al. Detection of small $(\leq 2 \mathrm{~cm})$ pancreatic adenocarcinoma and surrounding parenchyma: correlations between enhancement patterns at triphasic MDCT and histologic features. BMC Gastroenterol 2014;14:16.

15. D'Onofrio M, Zamboni GA, Malago R, Mantovani W, Principe F, Gallotti $A$, et al. Resectable pancreatic adenocarcinoma: is the enhancement pattern at contrast-enhanced ultrasonography a preoperative prognostic factor? Ultrasound Med Biol 2009;35:19291937.

16. National Comprehensive Cancer Network. NCCN Clinical Practice Guidelines in Oncology (NCCN guidelines): pancreatic adenocarcinoma [Internet]. Plymouth Meeting, PA: National Comprehensive Cancer Network; 2015 [cited 2019 Aug 20]. Available from: http://www.nccn.org/professionals/physician_gls/f_ guidelines.asp.

17. Liles JS, Katz MH. Pancreaticoduodenectomy with vascular resection for pancreatic head adenocarcinoma. Expert Rev Anticancer Ther 
2014;14:919-929.

18. Krishna NB, Tummala P, Mehan CD, Reddy AV, Hartman JA, Agarwal B. Small and potentially resectable focal pancreatic lesions noted on CT/MRI scans in nonjaundiced patients: likelihood of neoplasia and utility of EUS. J Gastrointest Surg 2012;16:793-800.

19. Haba S, Yamao K, Bhatia V, Mizuno N, Hara K, Hijioka S, et al. Diagnostic ability and factors affecting accuracy of endoscopic ultrasound-guided fine needle aspiration for pancreatic solid lesions: Japanese large single center experience. J Gastroenterol 2013;48:973-981.

20. Saif MW. Pancreatic neoplasm in 2011: an update. JOP 2011;12: 316-321.

21. Braden B, Jenssen C, D'Onofrio M, Hocke M, Will U, Moller K, et al. B-mode and contrast-enhancement characteristics of small nonincidental neuroendocrine pancreatic tumors. Endosc Ultrasound 2017;6:49-54.

22. National Comprehensive Cancer Network. NCCN Clinical Practice Guidelines in Oncology (NCCN guidelines): neurodendocrine tumors [Internet]. Plymouth Meeting, PA: National Comprehensive Cancer Network; 2015 [cited 2019 Aug 20]. Available from: http:// www.nccn.org/professionals/physician_gls/f_guidelines.asp.

23. Lee ES, Lee JM. Imaging diagnosis of pancreatic cancer: a state-ofthe-art review. World J Gastroenterol 2014;20:7864-7877.

24. ASGE Standards of Practice Committee, Eloubeidi MA, Decker GA, Chandrasekhara V, Chathadi KV, Early DS, et al. The role of endoscopy in the evaluation and management of patients with solid pancreatic neoplasia. Gastrointest Endosc 2016;83:17-28.

25. D'Onofrio $M$, Crosara S, Signorini $M$, De Robertis $R$, Canestrini $S$, Principe $F$, et al. Comparison between CT and CEUS in the diagnosis of pancreatic adenocarcinoma. Ultraschall Med 2013;34:377-381.

26. Khashab MA, Yong E, Lennon AM, Shin EJ, Amateau S, Hruban $\mathrm{RH}$, et al. EUS is still superior to multidetector computerized tomography for detection of pancreatic neuroendocrine tumors. Gastrointest Endosc 2011;73:691-696.

27. Yasuda I, Iwashita T, Doi S, Nakashima M, Moriwaki H. Role of EUS in the early detection of small pancreatic cancer. Dig Endosc 2011;23 Suppl 1:22-25.

28. Piscaglia F, Nolsoe C, Dietrich CF, Cosgrove DO, Gilja OH, Bachmann Nielsen $M$, et al. The EFSUMB guidelines and recommendations on the clinical practice of contrast enhanced ultrasound (CEUS): update 2011 on non-hepatic applications. Ultraschall Med 2012;33:33-59.

29. D'Onofrio M, Barbi E, Dietrich CF, Kitano M, Numata K, Sofuni A, et al. Pancreatic multicenter ultrasound study (PAMUS). Eur J Radiol 2012;81:630-638.

30. Kitano M, Yoshida T, Itonaga M, Tamura T, Hatamaru K, Yamashita Y. Impact of endoscopic ultrasonography on diagnosis of pancreatic cancer. J Gastroenterol 2019;54:19-32.

31. Krishna SG, Rao BB, Ugbarugba E, Shah ZK, Blaszczak A, Hinton $A$, et al. Diagnostic performance of endoscopic ultrasound for detection of pancreatic malignancy following an indeterminate multidetector CT scan: a systemic review and meta-analysis. Surg Endosc 2017;31:4558-4567.

32. Dietrich CF, Sahai AV, D'Onofrio M, Will U, Arcidiacono PG, Petrone MC, et al. Differential diagnosis of small solid pancreatic lesions. Gastrointest Endosc 2016;84:933-940.

33. Kanno A, Masamune A, Hanada K, Maguchi H, Shimizu Y, Ueki $T$, et al. Multicenter study of early pancreatic cancer in Japan. Pancreatology 2018;18:61-67.

34. Tanaka S, Nakaizumi A, loka T, Oshikawa O, Uehara H, Nakao M, et al. Main pancreatic duct dilatation: a sign of high risk for pancreatic cancer. Jpn J Clin Oncol 2002;32:407-411.

35. Izumi Y, Hanada K, Okazaki A, Minami T, Hirano N, Ikemoto J, et al. Endoscopic ultrasound findings and pathological features of pancreatic carcinoma in situ. Endosc Int Open 2019;7:E585-E593.

36. Terada S, Kikuyama M, Kawaguchi S, Kanemoto H, Yokoi $Y$, Kamisawa T, et al. Proposal for endoscopic ultrasonography classification for small pancreatic cancer. Diagnostics (Basel) 2019;9:E15.

37. Manta R, Nardi E, Pagano N, Ricci C, Sica M, Castellani D, et al. Pre-operative diagnosis of pancreatic neuroendocrine tumors with endoscopic ultrasonography and computed tomography in a large series. J Gastrointestin Liver Dis 2016;25:317-321.

38. James PD, Tsolakis AV, Zhang M, Belletrutti PJ, Mohamed R, Roberts DJ, et al. Incremental benefit of preoperative EUS for the detection of pancreatic neuroendocrine tumors: a meta-analysis. Gastrointest Endosc 2015;81:848-856.

39. Muller MF, Meyenberger C, Bertschinger P, Schaer R, Marincek B. Pancreatic tumors: evaluation with endoscopic US, CT, and MR imaging. Radiology 1994;190:745-751.

40. Shrikhande SV, Barreto SG, Goel M, Arya S. Multimodality imaging of pancreatic ductal adenocarcinoma: a review of the literature. HPB (Oxford) 2012;14:658-668.

41. DeWitt J, Devereaux B, Chriswell M, McGreevy K, Howard T, Imperiale TF, et al. Comparison of endoscopic ultrasonography and multidetector computed tomography for detecting and staging pancreatic cancer. Ann Intern Med 2004;141:753-763.

42. Dewitt J, Devereaux BM, Lehman GA, Sherman S, Imperiale TF. Comparison of endoscopic ultrasound and computed tomography for the preoperative evaluation of pancreatic cancer: a systematic review. Clin Gastroenterol Hepatol 2006;4:717-725.

43. Agarwal B, Abu-Hamda E, Molke KL, Correa AM, Ho L. Endoscopic ultrasound-guided fine needle aspiration and multidetector spiral CT in the diagnosis of pancreatic cancer. Am J Gastroenterol 2004;99:844-850.

44. Hewitt MJ, McPhail MJ, Possamai L, Dhar A, Vlavianos P, Monahan KJ. EUS-guided FNA for diagnosis of solid pancreatic neoplasms: a meta-analysis. Gastrointest Endosc 2012;75:319-331.

45. Chen G, Liu S, Zhao Y, Dai M, Zhang T. Diagnostic accuracy of 
endoscopic ultrasound-guided fine-needle aspiration for pancreatic cancer: a meta-analysis. Pancreatology 2013;13:298-304.

46. Chen J, Yang R, Lu Y, Xia Y, Zhou H. Diagnostic accuracy of endoscopic ultrasound-guided fine-needle aspiration for solid pancreatic lesion: a systematic review. J Cancer Res Clin Oncol 2012;138:1433-1441.

47. Puli SR, Bechtold ML, Buxbaum JL, Eloubeidi MA. How good is endoscopic ultrasound-guided fine-needle aspiration in diagnosing the correct etiology for a solid pancreatic mass?: a meta-analysis and systematic review. Pancreas 2013;42:20-26.

48. Sugiura R, Kuwatani M, Hirata K, Sano I, Kato S, Kawakubo $K$, et al. Effect of pancreatic mass size on clinical outcomes of endoscopic ultrasound-guided fine-needle aspiration. Dig Dis Sci 2019;64:2006-2013.

49. Dietrich CF, Ignee A, Frey H. Contrast-enhanced endoscopic ultrasound with low mechanical index: a new technique. $Z$ Gastroenterol 2005;43:1219-1223.

50. Dietrich CF, Burmester E. Contrast-enhanced ultrasound of small focal solid pancreatic lesions: a must! Endosc Ultrasound 2017;6:S106-S110.

51. Dietrich CF, Braden B, Hocke M, Ott M, Ignee A. Improved characterisation of solitary solid pancreatic tumours using contrast enhanced transabdominal ultrasound. J Cancer Res Clin Oncol 2008;134:635-643.

52. Dietrich $C F$, Ignee $A$, Braden $B$, Barreiros AP, Ott M, Hocke $M$. Improved differentiation of pancreatic tumors using contrastenhanced endoscopic ultrasound. Clin Gastroenterol Hepatol 2008;6:590-597.

53. Hocke M, Cui XW, Domagk D, Ignee A, Dietrich CF. Pancreatic cystic lesions: the value of contrast-enhanced endoscopic ultrasound to influence the clinical pathway. Endosc Ultrasound 2014;3:123-130.

54. D'Onofrio M, Biagioli E, Gerardi C, Canestrini S, Rulli E, Crosara $S$, et al. Diagnostic performance of contrast-enhanced ultrasound (CEUS) and contrast-enhanced endoscopic ultrasound (ECEUS) for the differentiation of pancreatic lesions: a systematic review and meta-analysis. Ultraschall Med 2014;35:515-521.

55. Gong TT, Hu DM, Zhu Q. Contrast-enhanced EUS for differential diagnosis of pancreatic mass lesions: a meta-analysis. Gastrointest Endosc 2012;76:301-309.

56. Kitano M, Kudo M, Yamao K, Takagi T, Sakamoto H, Komaki T, et al. Characterization of small solid tumors in the pancreas: the value of contrast-enhanced harmonic endoscopic ultrasonography. Am J Gastroenterol 2012;107:303-310.

57. He XK, Ding Y, Sun LM. Contrast-enhanced endoscopic ultrasound for differential diagnosis of pancreatic cancer: an updated metaanalysis. Oncotarget 2017;8:66392-66401.

58. Tanaka M, Fernandez-del Castillo C, Adsay V, Chari S, Falconi M, Jang JY, et al. International consensus guidelines 2012 for the management of IPMN and MCN of the pancreas. Pancreatology
2012;12:183-197.

59. Beyer-Enke SA, Hocke M, Ignee A, Braden B, Dietrich CF. Contrast enhanced transabdominal ultrasound in the characterisation of pancreatic lesions with cystic appearance. JOP 2010;11:427-433.

60. Sidhu PS, Cantisani V, Dietrich CF, Gilja OH, Saftoiu A, Bartels $E$, et al. The EFSUMB guidelines and recommendations for the clinical practice of contrast-enhanced ultrasound (CEUS) in nonhepatic applications: update 2017 (short version). Ultraschall Med 2018;39:154-180.

61. Sidhu PS, Cantisani V, Dietrich CF, Gilja OH, Saftoiu A, Bartels $E$, et al. The EFSUMB guidelines and recommendations for the clinical practice of contrast-enhanced ultrasound (CEUS) in nonhepatic applications: update 2017 (long version). Ultraschall Med 2018;39:e2-e44.

62. Jenssen C, Gilja OH, Serra AL, Piscaglia F, Dietrich CF, Rudd L, et al. European Federation of Societies for Ultrasound in Medicine and Biology (EFSUMB) Policy Document Development Strategy: clinical practice guidelines, position statements and technological reviews. Ultrasound Int Open 2019;5:E2-E10.

63. Dietrich CF, Averkiou M, Nielsen MB, Barr RG, Burns PN, Calliada $F$, et al. How to perform contrast-enhanced ultrasound (CEUS). Ultrasound Int Open 2018;4:E2-E15.

64. Hirche TO, Ignee A, Barreiros AP, Schreiber-Dietrich D, Jungblut $S$, Ott $M$, et al. Indications and limitations of endoscopic ultrasound elastography for evaluation of focal pancreatic lesions. Endoscopy 2008;40:910-917.

65. Ignee A, Atkinson NS, Schuessler G, Dietrich CF. Ultrasound contrast agents. Endosc Ultrasound 2016;5:355-362.

66. Dietrich CF, Dong Y, Jenssen C, Ciaravino V, Hocke M, Wang WP, et al. Serous pancreatic neoplasia, data and review. World Gastroenterol 2017;23:5567-5578.

67. Faccioli N, Dietrich CF, Foti G, Santi E, Comai A, D'Onofrio M. Activity-based cost analysis of including contrast-enhanced ultrasound (CEUS) in the diagnostic pathway of focal pancreatic lesions detected by abdominal ultrasound. Ultraschall Med 2019;40:618-624.

68. Barreiros AP, Dong Y, Ignee A, Wastl D, Dietrich CF. EchoScopy in scanning abdominal diseases: a prospective single center study. Med Ultrason 2019;21:8-15.

69. Frohlich E, Beller K, Muller R, Herrmann M, Debove I, Klinger C, et al. Point of care ultrasound in geriatric patients: prospective evaluation of a portable handheld ultrasound device. Ultraschall Med 2019 Apr 26 [Epub]. https://doi.org/10.1055/a-0889-8070.

70. Nielsen MB, Cantisani V, Sidhu PS, Badea R, Batko T, Carlsen J, et al. The use of handheld ultrasound devices: an EFSUMB position paper. Ultraschall Med 2019;40:30-39.

71. Dietrich CF, Hoffmann B, Abramowicz J, Badea R, Braden B, Cantisani $\mathrm{V}$, et al. Medical student ultrasound education: a WFUMB position paper, part I. Ultrasound Med Biol 2019;45:271-281. 
72. Dietrich CF, Goudie A, Chiorean L, Cui XW, Gilja OH, Dong Y, et al. Point of care ultrasound: a WFUMB position paper. Ultrasound Med Biol 2017:43:49-58.

73. Dighe M, Barr R, Bojunga J, Cantisani V, Chammas MC, Cosgrove D, et al. Thyroid ultrasound: state of the art part 1: thyroid ultrasound reporting and diffuse thyroid diseases. Med Ultrason 2017;19:79-93.

74. Dighe M, Barr R, Bojunga J, Cantisani V, Chammas MC, Cosgrove D, et al. Thyroid ultrasound: state of the art. Part 2: focal thyroid lesions. Med Ultrason 2017;19:195-210.

75. Cosgrove D, Barr R, Bojunga J, Cantisani V, Chammas MC, Dighe M, et al. WFUMB guidelines and recommendations on the clinical use of yltrasound elastography: Part 4. thyroid. Ultrasound Med Biol 2017;43:4-26.

76. Barr RG, Cosgrove D, Brock M, Cantisani V, Correas JM, Postema AW, et al. WFUMB guidelines and recommendations on the clinical use of ultrasound elastography: Part 5. Prostate. Ultrasound Med Biol 2017;43:27-48.

77. Shiina T, Nightingale KR, Palmeri ML, Hall TJ, Bamber JC, Barr RG, et al. WFUMB guidelines and recommendations for clinical use of ultrasound elastography: Part 1: basic principles and terminology. Ultrasound Med Biol 2015;41:1126-1147.

78. Ferraioli G, Filice C, Castera L, Choi BI, Sporea I, Wilson SR, et al. WFUMB guidelines and recommendations for clinical use of ultrasound elastography: Part 3: liver. Ultrasound Med Biol 2015;41:1161-1179.

79. Barr RG, Nakashima K, Amy D, Cosgrove D, Farrokh A, Schafer F, et al. WFUMB guidelines and recommendations for clinical use of ultrasound elastography: Part 2: breast. Ultrasound Med Biol 2015;41:1148-1160.

80. Dietrich CF, Bamber J, Berzigotti A, Bota S, Cantisani V, Castera L, et al. EFSUMB guidelines and recommendations on the clinical use of liver ultrasound elastography, update 2017 (short version). Ultraschall Med 2017;38:377-394.

81. Dietrich CF, Bamber J, Berzigotti A, Bota S, Cantisani V, Castera L, et al. EFSUMB guidelines and recommendations on the clinical use of liver ultrasound elastography, update 2017 (long version). Ultraschall Med 2017;38:e16-e47.

82. Cosgrove D, Piscaglia F, Bamber J, Bojunga J, Correas JM, Gilja OH, et al. EFSUMB guidelines and recommendations on the clinical use of ultrasound elastography. Part 2: clinical applications. Ultraschall Med 2013;34:238-253.

83. Bamber J, Cosgrove D, Dietrich CF, Fromageau J, Bojunga J, Calliada $F$, et al. EFSUMB guidelines and recommendations on the clinical use of ultrasound elastography. Part 1: basic principles and technology. Ultraschall Med 2013;34:169-184.

84. Saftoiu A, Gilja OH, Sidhu PS, Dietrich CF, Cantisani V, Amy D, et al. The EFSUMB guidelines and recommendations for the clinical practice of elastography in non-hepatic applications: update 2018. Ultraschall Med 2019;40:425-453.
85. Dietrich CF, Bibby E, Jenssen C, Saftoiu A, Iglesias-Garcia J, Havre RF. EUS elastography: how to do it? Endosc Ultrasound 2018;7:20-28.

86. Dietrich CF, Barr RG, Farrokh A, Dighe M, Hocke M, Jenssen C, et al. Strain elastography: how to do it? Ultrasound Int Open 2017;3:E137-E149.

87. Ignee A, Jenssen C, Arcidiacono PG, Hocke M, Moller K, Saftoiu A, et al. Endoscopic ultrasound elastography of small solid pancreatic lesions: a multicenter study. Endoscopy 2018;50:1071-1079..

88. Dietrich CF, Hirche TO, Ott M, Ignee A. Real-time tissue elastography in the diagnosis of autoimmune pancreatitis. Endoscopy 2009; $41: 718-720$

89. Dong $Y$, D'Onofrio $M$, Hocke $M$, Jenssen $C$, Potthoff $A$, Atkinson $\mathrm{N}$, et al. Autoimmune pancreatitis: imaging features. Endosc Ultrasound 2018;7:196-203.

90. Dong Y, Potthoff A, Klinger C, Barreiros AP, Pietrawski D, Dietrich CF. Ultrasound findings in autoimmune hepatitis. World I Gastroenterol 2018;24:1583-1590.

91. Hocke M, Ignee A, Dietrich CF. Three-dimensional contrastenhanced endoscopic ultrasound for the diagnosis of autoimmune pancreatitis. Endoscopy 2011;43 Suppl 2 UCTN:E381-E382.

92. Hocke M, Ignee A, Dietrich CF. Contrast-enhanced endoscopic ultrasound in the diagnosis of autoimmune pancreatitis. Endoscopy 2011;43:163-165.

93. Dong $Y$, Jurgensen $C$, Puri $R$, D'Onofrio $M$, Hocke $M$, Wang WP, et al. Ultrasound imaging features of isolated pancreatic tuberculosis. Endosc Ultrasound 2018;7:119-127.

94. Barreiros AP, Braden B, Schieferstein-Knauer C, Ignee A, Dietrich CF. Characteristics of intestinal tuberculosis in ultrasonographic techniques. Scand I Gastroenterol 2008;43:1224-1231.

95. Goertz RS, Schuderer J, Strobel D, Pfeifer L, Neurath MF, Wildner D. Acoustic radiation force impulse shear wave elastography (ARFI) of acute and chronic pancreatitis and pancreatic tumor. Eur J Radiol 2016;85:2211-2216.

96. Onoyama T, Koda M, Fujise Y, Takata T, Kawata S, Okamoto T, et al. Utility of virtual touch quantification in the diagnosis of pancreatic ductal adenocarcinoma. Clin Imaging 2017;42:64-67.

97. Park MK, Jo J, Kwon H, Cho JH, Oh JY, Noh MH, et al. Usefulness of acoustic radiation force impulse elastography in the differential diagnosis of benign and malignant solid pancreatic lesions. Ultrasonography 2014;33:26-33.

98. D'Onofrio M, De Robertis R, Crosara S, Poli C, Canestrini S, Demozzi $\mathrm{E}$, et al. Acoustic radiation force impulse with shear wave speed quantification of pancreatic masses: a prospective study. Pancreatology 2016;16:106-109.

99. Falconi M, Bartsch DK, Eriksson B, Kloppel G, Lopes JM, O'Connor $J M$, et al. ENETS Consensus Guidelines for the management of patients with digestive neuroendocrine neoplasms of the digestive system: well-differentiated pancreatic non-functioning tumors. Neuroendocrinology 2012;95:120-134. 